\title{
NEOPRODUTIVISMO E AMESQUINHAMENTO DA FORMAÇÃO DOCENTE
}

\author{
Melânia Mendonça Rodrigues
}

\begin{abstract}
RESUMO
Decorrente da pesquisa nacional "A formação para o trabalho simples no Brasil contemporâneo: da Educação para todos ao Todos pela Educação", desenvolvida pelo Coletivo de Estudos em Política Educacional, o artigo se volta ao objetivo de analisar, no âmbito das políticas educacionais implementadas no Brasil nas últimas três décadas, as políticas de formação de professores para a educação básica, entendendo-os como intelectuais orgânicos da formação para o trabalho simples. Desse objetivo mais geral, aqui se destacam as diretrizes e propostas do Banco Mundial para essas políticas, abordando, mais detidamente, a última publicação desse organismo sobre a matéria. A análise do documento demonstra continuidades, nos anos 2000, nas propostas do BM para a formação docente formuladas nos anos 1990: lógica economicista, concepção aligeirada da formação, com um caráter nitidamente instrumental. Por outro lado, aponta o agravamento das ameaças de a formação universitária ser substituída por "rotas alternativas" ou "programas de imersão" ou, no limite, pela certificação, por meio de provas de ingresso no magistério, permitindo atrair profissionais de outras áreas para curtos períodos de exercício profissional como professores.

Palavras-chave: Formação de professores; Banco Mundial; Política educacional; Educação básica.
\end{abstract}

\section{NEW PRODUCTION PROCESS AND DEPRECIATION IN FORMATION OF TEACHERS}

\begin{abstract}
Current of national research "The formation for simple work in contemporary Brazil: from Education for everybody to Everybody for Education", developed by the Group of Collective Studies in Educational Politics, this article has as objective to analyze, in the ambit of educational politics implemented in Brazil in the last three decades, the politics of teachers formation for elementary school, understand them as organic intellectuals of simple work formation. For this general objective, it is detaches the directresses and proposals of World Bank for these politics, approaching, with more attention, the last publication of this organism about the subject. The document analysis shows continuations, in the 2000 year, in WB proposals to teachers formation formulated in the 1990 decade: new liberal economic view, hastened formation conception, with a clearly instrumental character. In another aspect, this article shows the threat aggravation of academic formation be substituted by "alternative ways" or "immersion programs" or, in the last case, for certification, by mastership ingress tests, allowing to attract professionals of another areas for short period of professional practice as teachers.
\end{abstract}

Keywords: Teachers formation; World Bank; Educational Politics; Elementary education. 


\section{INTRODUÇÃO}

Decorrente das mudanças societárias do estágio da acumulação flexível ou da mundialização financeira capitalista, desenvolve-se, a partir dos anos 1990, um processo de reforma da educação brasileira que, referenciado no ideário neoliberal e seguindo diretrizes dos organismos internacionais, objetiva conformar a educação escolar, de modo mais global, à concepção neoprodutivista (SAVIANI, 2008), no âmbito da qual, a organização da escola e do trabalho docente deve-se pautar, primordialmente, pelo binômio competitividade e produtividade, nos moldes empresariais.

Em decorrência, "a escola brasileira foi se direcionando também para a formação de subjetividades coletivas, com vistas à construção de um amplo consenso social em torno da concepção de mundo burguesa em tempos de novo imperialismo" (NEVES et al., 2011, p. 7). Norteada por esse objetivo mais geral, a reforma retoma a teoria do capital humano, em sua versão atualizada (FRIGOTTO, 1984, 1995; PIRES, 2005), e adota a pedagogia das competências como balizamento pedagógico de seu projeto educacional.

Assim orientados, os dois governos FHC procederam a uma substantiva reconfiguração da educação escolar nos níveis básico e superior, incluída a formação técnico-profissional, buscando adequar a formação para o trabalho simples e para o trabalho complexo ${ }^{1}$ às exigências postas pelo - já referido - atual momento da acumulação do capital.

Numa linha de continuidade dos governos FHC, a política de educação do primeiro governo Luís Inácio da Silva, ainda em consonância com as diretrizes dos organismos internacionais, conferiu grande ênfase à alfabetização e à qualidade da educação básica, em especial ao combate à reprovação. Voltou-se, ainda, para o fortalecimento da educação profissional, e para a reforma da educação superior.

No segundo governo Lula da Silva, duas medidas da política educacional concorreram para expandir a formação para o trabalho simples: a implementação do Fundo de Desenvolvimento da Educação Básica e de Valorização dos Profissionais da Educação (FUNDEB) e a ampliação da obrigatoriedade escolar para o nível médio, contribuindo, formalmente, para a universalização da escolaridade básica.

Por outro lado, a política de formação para o trabalho simples, ao longo do segundo governo Lula da Silva, apresenta uma nova peculiaridade, a atuação de setores do empresariado brasileiro na formulação e na execução da política educacional e a prestação de serviços, realizada por empresas privadas, na formação continuada de professores e na promoção de eventos pedagógicos.

Objetivando compreender a política educacional de formação para o trabalho simples nesse contexto, o Coletivo de Estudos de Política Educacional ${ }^{2}$ desenvolve, desde o ano de 2010, a pesquisa nacional "A formação para o trabalho simples no Brasil contemporâneo: da Educação para todos ao Todos pela Educação", tendo como eixos as análises das seguintes determinações:

- as diretrizes dos organismos internacionais para a educação básica na América Latina;

- papel das instâncias federativas na formulação e execução das políticas de educação básica; 
- as diretrizes educacionais e as estratégias políticas do empresariado brasileiro em relação à educação básica, e

- as diretrizes dos organismos internacionais e das instâncias governamentais para a formação dos professores da educação básica, entendidos como os intelectuais orgânicos da formação para o trabalho simples no Brasil contemporâneo.

Inscrevendo-se no âmbito desse último eixo, o presente artigo sistematiza reflexões acerca das diretrizes e orientações emanadas do Banco Mundial para a formação dos professores, focalizando - ante a necessidade de adequação aos limites de extensão do texto - o documento Profesores excelentes: cómo mejorar el aprendizaje en América Latina y el Caribe (BRUNS; LUQUE, 2014), por se tratar de um texto algo recente e de ainda - restrita discussão nos meios acadêmicos.

Seguindo o procedimento adotado na análise documental, durante a pesquisa, ancorado em categorias metodológicas da concepção dialética (WACHOWICZ, 2001), a abordagem do referido documento, aqui apresentada, respeita os alertas formulados por Arnaut de Toledo; Gimenez (2009) e Evangelista (s.d.), segundo os quais,

Os documentos "não falam por si" e também não são apenas fontes de informação histórica. (...) Para o pesquisador, as informações que podem trazer vão além do imediatamente observável. É necessário analisá-los estruturalmente e historicamente" (ARNAUT DE TOLEDO; GIMENEZ, 2009, p. 116).

[...] tais materiais - oriundos do aparelho de Estado, de organizações multilaterais e de agências e intelectuais (...) expressam não apenas diretrizes para a educação, mas articulam interesses, projetam políticas, produzem intervenções sociais.

O que a fonte silencia pode ser mais importante do que o que proclama, razão pela qual nosso esforço deve ser o de apreender o que está dito e o que não está. Ler nas entrelinhas parece recomendação supérflua, entretanto deve-se perguntar-lhe o que oculta e por que oculta: fazer sangrar a fonte (EVANGELISTA, s. d., p. 1-2; p. 10).

Dessa forma, como uma primeira aproximação ao objeto de estudo, procede-se, na sequência, a uma contextualização mais geral dos nexos dos organismos internacionais com a política de formação de professores, ao longo das últimas três décadas.

\section{ORGANISMOS INTERNACIONAIS E A FORMAÇÃO DE PROFESSORES PARA A EDUCAÇÃO BÁSICA}

No contexto societário mais amplo das últimas décadas do século XX, as mudanças nas esferas econômicas, sociais, políticas, culturais e educacionais - oriundas da evolução capitalista, e, sobretudo, das transformações técnico-científicas aceleradas fruto da III Revolução Científica e Tecnológica, que são características da atual etapa de desenvolvimento do modo de produção capitalista, engendram o fenômeno chamado de globalização ou mundialização de mercado.

Com o acelerado processo de reestruturação e integração da economia, a busca da eficiência e competitividade, bem como com a desregulamentação do comércio entre os países, observa-se a destruição das fronteiras nacionais e uma liberdade de trânsito para mercadorias e capitais, dando origem a uma espécie de mercado universal. 
Com a crise de endividamento dos países do Terceiro Mundo na década de 1980, principalmente com credores privados, tanto o BM (Banco Mundial) ${ }^{3}$, quanto os demais organismos internacionais de financiamento, como o FMI (Fundo Monetário Internacional), entram em cena, propiciando um contexto político favorável para que o Banco assumisse um papel central no financiamento dos países endividados e em desenvolvimento, por meio de programas de ajuste estrutural.

Mediante a concessão de financiamento, e para a garantia de novos financiamentos, o Banco passa a impor uma série de condicionalidades, "mediante [as quais], o BM (tal como o FMI) passou a intervir diretamente na formulação da política interna e a influenciar a própria legislação dos países" (SOARES, 1996, p. 21). Sendo assim, passa a exercer amplo controle sobre eles. No Brasil, desde o primeiro empréstimo tomado em 1945, é considerável o aumento do setor educacional, quando comparado a outros setores (TOMMASI; WARDE; HADDAD, 1996).

Além de ter se tornado "o maior captador mundial não soberano de recursos financeiros" (LEHER, 2011, p. 4), o Banco Mundial concentra suas atenções nos processos educacionais como estratégia principal para consolidação da nova ordem econômica mundial pautada no neoliberalismo de mercado. É esse Banco quem define as diretrizes para a educação, compreendendo-a como uma máquina estratégica para controle da mente "do pequeno núcleo de intelectuais, dos educados e dos semieducados" (LEHER, 2011, p. 2).

Nesse contexto, o BM estabelece as orientações para a educação e a formação dos intelectuais para o exercício da docência na educação básica, pois "cabe à educação básica assegurar a base sólida para a educação futura" (SHIROMA; MORAES; EVANGELISTA, 2000, p. 67).

Tais orientações correspondem ao conjunto de reformas consensuais entre os principais organismos internacionais reunidos em Washington no final dos anos 1980, conhecido como Consenso de Washington, e reafirmado pela Conferência Mundial de Educação para Todos, ocorrida na Tailândia, em Jomtien, em 1990, e pela Cúpula Mundial de Educação para Todos, ocorrida no Senegal, em, Dacar, em 2000, ambas promovidas pelo UNICEF (Fundo das Nações Unidas para Infância), pela UNESCO (Organização para a Educação, a Ciência e a Cultura das Nações Unidas) e pelo PNUD (Programa das Nações Unidas para o Desenvolvimento) e o Banco Mundial.

O pacote de reformas para a educação básica, proposto pelo Banco Mundial, contém, dentre outros, os seguintes elementos centrais, segundo Haddad (2008):

a) prioridade na educação primária;

b) melhoria da eficácia da educação;

c) ênfase nos aspectos administrativos;

d) descentralização e autonomia das instituições escolares, entendida como transferência de responsabilidades de gestão e de captação de financiamento, enquanto ao Estado caberia manter centralizadas as funções de fixar padrões, facilitar os insumos que influenciam o rendimento escolar, adotar estratégias flexíveis para a aquisição e uso de tais insumos e monitorar o desempenho escolar;

e) a análise econômica como critério dominante na definição das estratégias e, cabe destacar, das políticas públicas educacionais. 
É com base nesse critério, por exemplo, que o Banco questiona se o aumento do salário do professor, assim como o número de alunos por professor, resulta em melhoria ou não na qualidade do ensino, argumentando que "segundo suas pesquisas, a qualidade das instalações escolares ou do material didático tem um impacto cerca de dez vezes maior sobre a qualidade do ensino do que o aumento salarial aos professores" (HADDAD, 2008, p. 27), descartando a possibilidade de que a valorização do professor, em termos de remuneração, seja uma das garantias para a qualidade educacional.

As propostas do Banco Mundial para a educação visam, pois, atender às demandas do capital, vinculando a educação ao mercado de trabalho, razão por que consideram necessário ensinar (docentes) e adquirir (discentes) as competências que possibilitarão o desenvolvimento de aptidões, valores e atitudes, de acordo com as novas demandas de reprodução técnico-científica e ético-política do capital, portanto, formando trabalhadores adaptáveis, capazes de adquirir novos conhecimentos sem dificuldades e, acima de tudo, atendendo à demanda da economia.

Em se tratando, mais especificamente, da formação docente, Pansardi (2011) formula uma crítica bastante lúcida, cuja síntese é transcrita, parcialmente, a seguir.

Visto como um "mal necessário", como importante, mas secundário, o professor assim como a própria pedagogia, devem ser deslocados do centro do processo educativo. $\mathrm{O}$ uso dos processos tecnológicos e a educação a distância servem não só como forma de baratear a formação docente como também para colocá-los no centro do processo de aprendizagem.

Assim, se soma a busca de uma formação mais prática onde se valorizam as experiências dos professores em detrimento a uma formação mais teórica. Nesta mesma linha se insere um modelo pedagógico baseado na incorporação de "competências". A formação de professores, se insere na lógica neoliberal da eficácia e eficiência, reduzindo-se o custo a reduzir o tempo, ao mesmo tempo que garante um caráter mais pragmático de sua formação (PANSARDI, 2011, p. 138, destaques do original).

Também se podem apontar, como organismos de relevante ingerência nas políticas educacionais brasileiras, o PREAL (Programa de Promoção da Reforma Educativa na América Latina e Caribe) e a OCDE (Organização para a Cooperação e o Desenvolvimento Econômico). Possuem como meta interferir na formação de professores da educação básica para as novas demandas técnico-organizacionais do trabalho na perspectiva capitalista, alegando ser necessário um novo tipo de trabalhador, "os quais as escolas e universidades devem se preparar para formar" (SOUZA, 2009, p. 63).

O PREAL, fundado em 1996, é codirigido pela USAID e BID e, frequentemente, realiza trabalhos de pesquisa sob encomenda do Banco Mundial ou com financiamento desse organismo. Sediado no Chile, tem no Brasil uma sucursal, filiada à Fundação Getúlio Vargas. Analisando as propostas desse organismo, relativas à formação docente, Werlang e Viriato concluem que

[...] as orientações para a política de formação de professorespropostas nos documentos [...] estão relacionadas à priorização do conhecimento sobre a prática, às cobranças individualizadas, a regulação e a fragmentação do trabalho pedagógico, as competências como política de 
formação e a avaliação docente (WERLANG; VIRIATO, 2012, p. 11, itálico no original).

A OCDE "como um organismo multilateral, deu-se a partir da Organização para a Cooperação Econômica Europeia (1947) no âmbito do Plano Marshall, construído pelo governo dos EUA para oferecer auxilio econômico (...) aos países europeus que foram devastados pela $2^{a}$ Guerra Mundial" (SOUZA, 2009 p. 34). Possui 30 países em um único fórum, voltado à elaboração e acompanhamento de políticas econômicas e sociais, do qual o Brasil faz parte, atuando como colaborador de políticas na área de educação.

Maués (2011) chama a atenção para a relevância do papel que a OCDE vem assumindo no tocante às políticas educacionais, seja pela realização e divulgação de pesquisas, pela publicação de documentos ou "pelo 'aconselhamento' oferecido tanto aos países membros como aos outros" (p.76, destaque no original). Na apreciação da autora,

[...] as políticas de formação expressas nos documentos da OCDE (...) têm a característica de imprimirem regulações pós-burocráticas em função da valorização instrumental, da ênfase na eficácia e na performance que são inerentes às concepções apresentadas e pela adoção de formas de controle que incidem sobre os resultados, com um discurso de autonomia sobre o processo (MAUÉS, 2011, p. 83).

Seguindo a orientação e financiado pelos organismos internacionais, o MEC (Ministério da Educação), a partir do primeiro governo $\mathrm{FHC}$, "chamou a si a responsabilidade de incluir no ensino fundamental toda a população com idade para frequentar esse nível de ensino (...), tornou-se 'pedagogo' do 'treinamento em serviço' do professor" (BRZEZINSKI, 2010, p. 168, destaques no original).

Houve incentivos de programas com a finalidade de capacitar leigos atuantes na educação básica, leigos estes que nem "sequer tinham integralizado sua escolaridade no próprio ensino fundamental, portanto, não tinham completado estudos da $1^{\mathrm{a}}$ à $8^{\mathrm{a}}$ série do primeiro grau, nível em que davam aulas" (BRZEZINSKI, 2010, p. 170). Também se destacam as iniciativas na direção da instituição de diretrizes curriculares nacionais para a formação de professores no nível superior, bem como criação da Universidade Aberta do Brasil (UAB-Rede Virtual), para atuar na formação - inicial e continuada - de professores, na modalidade de educação a distância.

Em síntese, os apontamentos ora sistematizados, à guisa de uma visão geral, permitem constatar que as diretrizes para formação de professores, formuladas pelos organismos multilaterais, o Banco Mundial à frente, formuladas durante os anos 1990, "privilegia[m] aspectos econômicos, baseada[s] em análises de custo-benefício, em que a formação docente é pensada em termos da melhor forma de se produzir um profissional competente [apenas] tecnicamente" (SANTOS, 2000, p. 174, acréscimos desta citação).

\section{PROFESSORES EXCELENTES?}

Lançado em 2014, pelo Grupo Banco Mundial, integando a Serie del Foro sobre Desarrollo de América Latina, o livro Profesores excelentes: cómo mejorar el aprendizaje en América Latina y el Caribe constitui a mais recente publicação desse organismo sobre a formação e a profissão docente. Conforme esclarecem seus autores e coordenadores da pesquisa, Barbara Bruns e Javier Luque, trata-se de um trabalho realizado por uma equipe 
no âmbito do Programa de Estudos Regionais sobre América Latina e Caribe, do Banco Mundial, motivado pela compreensão de que a

[...] onda de reformas inovadoras nas políticas docentes que se estendeu por toda América Latina e Caribe na década de 2000 merecia ser investigada e que os resultados desses estudos deveriam ser conhecidos pelos funcionários encarregados de formular políticas em outras regiões (BRUNS; LUQUE, 2014, p. xiii).

Justificando a relevância desse estudo, os autores enfatizam o papel dos professores na sociedade, reconhecendo-os, "cada vez mais, como atores chave nos esforços da região para melhorar a qualidade e os resultados educativos" (BRUNS; LUQUE, 2014, p. 1). Logo a seguir, e já expressando a lógica economicista inerente ao organismo patrocinador do estudo, os autores ressaltam o fato de que "embora a importância de um bom ensino possa parecer evidente, nas pesquisas educacionais, nos últimos 10 anos, se começou a quantificar o grande impacto econômico da qualidade dos professores" (BRUNS; LUQUE, 2014, p. 1). Em consequência, afirmam os autores,

Los Gobiernos de todo el mundo ponen bajo la lupa, en medida creciente, la calidad y el desempeño de los profesores. América Latina y el Caribe no es la excepción; de hecho, en algunas esferas clave de las políticas docentes, la región está a la vanguardia de las reformas mundiales (BRUNS; LUQUE, 2014, p.1).

$\mathrm{Na}$ sequência dessas constatações introdutórias, e seguindo roteiro comum às produções do Banco, o documento ora referenciado apresenta um panorama do que denomina como qualidade dos professores da educação básica, base empírica para a formulação das propostas do organismo para a formação docente ${ }^{4}$ na Região.

Como exposto no Prólogo, tal panorama foi traçado com respaldo em estudos que compuseram "la base de datos comparables a nivel mundial sobre práctica docente en el aula más grande de la historia, con observaciones de más de 15000 profesores de 7 países de América Latina y el Caribe" (FAMILIAR et al., 2014, p. XII). Os dois primeiros capítulos da publicação, ¿Quiénes son los profesores de América Latina y el Caribe? eDentro de las aulas de América Latina y el Caribe, apresentam os dados coletados, traçando o perfil dos professores e das práticas docentes no universo pesquisado, na ótica do Banco.

Sobrelevam, nesses dois capítulos, aspectos negativos acerca dos profissionais e da carreira do magistério, caracterizados por:

- "elevados níveis de educação, mas escassas capacidades cognitivas"- os ingressantes na carreira docente são "academicamente menos sólidos que o conjunto geral da educação superior" (p. 7);

- predomínio de "mulheres, de posição socioeconômica relativamente baixa" - um "conjunto de estudantes que possivelmente teve escasso contato com outras profissões ao longo de sua vida e, em consequência, tem aspirações acadêmicas mais limitadas" (p. 7);

- salários relativamente baixos - os docentes, durante toda a década de 2000, perceberam salários "entre $10 \%$ a $50 \%$ mais baixos que os de outros profissionais 'equivalentes'. Não obstante, os professores trabalham um número significativamente menor de horas" (p. 8, destaque no original); 
- trajetória linear da remuneração - os salários docentes aumentam lentamente, desconsiderando diferenças de capacidade, talento e de experiência, gerando distorções como "indivíduos [...] menos produtivos ganham relativamente mais como professores, enquanto aqueles cujos atributos fazem-nos muito produtivos tendem a ganhar relativamente menos" (p. 9).

Em se considerando a formação docente, o documento está permeado por diversas propostas, das quais são destacadas, textualmente, as consideradas como de maior relevância:

- “os programas de formação centrados no trabalho que os professores enfrentarão realmente nas aulas dão como resultado professores mais eficazes no primeiro ano e maior aprendizagem entre seus alunos" (BOYD et al., 2009, apud BRUNS; LUQUE, 2014, p.27);

- "parâmetros nacionais para o ensino, em que se articulem 'o que um professor deve saber e poder fazer"” (p. 29, destaque no original);

- "exame de certificação ou prova de capacidade para selecionar os candidatos a ocupar postos docentes" (p. 29). [...]

Os "exames de egresso", prestados ao se concluir o programa de formação também podem contribuir para melhorar a contratação dos professores, verificar o nível dos graduados ao longo do tempo e manifestar as diferenças de qualidade entre os institutos de formação. A Prova Inicia do Chile, estabelecida em 2008, e o exame nacional de professores que se está elaborando no Brasil (Prova Nacional de Concurso para o Ingresso na Carreira Docente) são exemplos disso (p. 30-31, destaques do original);

- "evitar, por completo, os institutos de educação de baixa qualidade e contratar professores que se tenham formado em outras disciplinas, prática que se conhece como 'certificação alternativa'.

Esta estratégia foi chave na rápida melhora da qualidade docente na cidade de Nova York e se aplica amplamente em outros distritos escolares urbanos dos Estados Unidos que têm dificuldades para atrair professores para o trabalho com populações desfavorecidas. Em diversos estudos rigorosos realizados nos Estados Unidos se chegou, em geral, à conclusão de que os alunos de professores com certificações alternativas, em particular os do programa Teach for America (Ensina para a América), têm um desempenho igual ou melhor que os de professores contratados pelas vias normais (p. 31).

Em nítida contraposição à valorização da "rota alternativa" (ZEICHNER, 2013), a formação inicial prévia ao ingresso na profissão, segundo o documento,

[...] não consegue transmitir suficiente domínio dos conteúdos nem uma pedagogia centrada no aluno, está distanciada do sistema escolar e da formulação das políticas educativas, e só prevê a exposição prática ao trabalho nas escolas ao final da formação e, em alguns casos, não a contempla em absoluto (UNESCO, 2012, apud BRUNS; LUQUE, 2014, p. 27) 
Em contrapartida, os autores consideram como um avanço o fato de vários países do subcontinente haverem implementado, desde o ano de 2007, seções da rede Teach for All (Ensina para Todos), uma vez que, por meio desse programa, "Chile, Peru,México, Colômbia, Argentina e Brasil recrutaram profissionais de primeiro nível, de outras disciplinas, [...] dispostos a dedicarem dois anos ao ensino em escolas de zonas sumamente desfavorecidas" (BRUNS; LUQUE, 2014,p. 31).

O que o documento não explicita, entretanto, é o modo como esses professores são treinados, acerca de cuja precariedade não restam dúvidas, quando se observa a descrição constante do próprio sítio brasileiro da rede, transcrita por Freitas.

\begin{abstract}
Antes de assumir uma sala de aula, o "ensina" passa por um treinamento intensivo dedois meses, em janeiro e fevereiro. O conteudo e desenvolvido com base nos 20 anos desucesso da rede Teach for All e atualizado com o pensamento de educadores brasileiros.Neste treinamento inicial, que chamamos de Instituto de Verao, os "ensinas" planejam seus cursos e já entram em sala de aula, sempre acompanhados de perto por tutoresexperientes. Toda a pratica e avaliada e discutida em grupo, num processo de feedbackconstante (ENSINA! apud FREITAS, 2012, p. 394).
\end{abstract}

Como alternativa à ineficiência da formação inicial prévia ao exercício profissional, alegando respaldo "na bibliografia acadêmica" referente "aos sistemas educativos "que estão melhorando", o documento aponta, mais especificamente, "quatro estratégias amplas mais pertinentes" para a formação docente na América Latina e no Caribe:

- enfoques "com guia" - capacitação que busca preparar os professores para empregar estratégias pedagógicas específicas e materiais complementares no ensino de um plano de estudos diário bem definido;

- domínio de conteúdos - capacitação centrada em suprir as lacunas ou aprofundar os conhecimentos dos professores sobre as matérias que ministram e sobre como ensiná-los eficazmente;

- gestão de aula - capacitação centrada em melhorar a eficácia dos professores na aula, através do planejamento das aulas, do uso eficaz do tempo, das estratégias para manter a atenção dos estudantes e das técnicas de ensino mais eficazes;

- colaboração entre colegas - ocasiões para que pequenos grupos de professores (tanto de uma mesma escola como de diversos estabelecimentos) se reúnam para observar e aprender as práticas dos demais e colaborar no desenvolvimento de programas, estratégias de avaliação dos estudantes, investigações e outras atividades que contribuem para melhorar a qualidade do sistema e o desenvolvimento profissional dos professores (p. 37, destaque no original).

O documento apresenta, ainda, experiências de programas de capacitação em serviço, desenvolvidas na Região, centrados em conhecimentos específicos requeridos para um ensino eficaz, e destaca o exemplo do Brasil:

Um número crescente de ministérios (e secretarias no Brasil) está criando institutos que promovem formação pedagógica em serviço, com o fim de 
tomar o controle direto dos conteúdos e da implementação do desenvolvimento profissional docente. Embora ainda seja cedo para avaliar a eficácia desses institutos, produziu-se uma visível mudança em favor dos programas de desenvolvimento profissional que abordam de maneira direta os problemas detectados. O uso dos dados extraídos das avaliações docentes para determinar as prioridades de capacitação; o aproveitamento da colaboração com organizações não governamentais, grupos de estudo e outros prestadores que não trabalham nos departamentos universitários de educação; e uma avaliação rigorosa, pelo menos, das iniciativas de capacitação mais importantes contribuirá para que o investimento nesta esfera seja mais eficaz em função dos custos, algo essencial para melhorar com mais rapidez a qualidade do conjunto atual de professores (p. 38).

Conforme se pode depreender do ora exposto, o Banco Mundial legitima, no documento ora abordado, "[a] visão pragmatista [que] se instala cada vez mais nas agências formadoras do professor, restringindo sua formação aos aspectos práticos das metodologias" (FREITAS, 2012, p. 394).

\section{CONSIDERAÇÕES}

A análise do documento Profesores excelentes: cómo mejorar el aprendizaje en América Latina y el Caribe demonstra que as propostas do BM para a formação docente mantêm consonância com aquelas formuladas nos anos 1990, uma vez que seguem pautadas na lógica economicista, defendendo o aligeiramento da formação, quando priorizam a formação continuada, em lugar da inicial, com um caráter nitidamente instrumental.

Tal constatação reforça o entendimento de Neves (2013), para quem

$\mathrm{Na}$ atualidade brasileira, as políticas educacionais em geral e, mais especificamente, as políticas de formação inicial e continuada de professores têm [na] dimensão política da prática docente uma forte determinação. A metamorfose ocorrida nas relações de poder no país a partir de 1995 e a solidez alcançada pelo projeto capitalista neoliberal permitem assegurar que o professor, em todos os níveis de ensino, vem se constituindo, no capitalismo contemporâneo, em importante intelectual orgânico da nova pedagogia da hegemonia (p. 4-5).

Para além das questões levantadas, as indicações do documento do Banco Mundial indicam um risco iminente de a formação universitária ser substituída por "rotas alternativas" ou "programas de imersão" como os que já se encontram em desenvolvimento nos Estados Unidos e em alguns outros países, formando "professores como meros executores de scripts de ensino elaborados por outros" (COMPTON; WEINER, 2008, apud ZEICHNER, 2013, p. 35).

No limite, há o risco de que a formação seja substituída pela certificação, por meio de provas de ingresso no magistério, permitindo atrair profissionais de outras áreas para curtos períodos de exercício profissional como professores "em escolas de zonas sumamente desfavorecidas", como destacado no documento do BM aqui focalizado, reforçando, perversamente, as desigualdades sociais. 
A formação de professores encontra-se, pois, no momento, ameaçada de forte retrocesso, consubstanciado, dentre outras formas, nas propostas dos organismos multilaterais como o Banco Mundial. Contra ele, devemos nos voltar, coletivamente, todos os que lutamos pela educação como espaço de humanização e de emancipação.

\section{Referências}

ARNAUT DE TOLEDO, Cézar de Alencar; GIMENEZ, José Carlos. Educação e pesquisa: fontes e documentos. In: CASIMIRO, Ana Palmira Bittencourt S.; LOMBARDI, José Claudinei; MAGALHÃES, Lívia Diana Rocha (org.). A pesquisa e a preservação de arquivos e fontes para a educação, cultura e memória. Campinas: Editora Alínea, 2009, p. 109-125.

BRUNS, Barbara; LUQUE, Javier. Profesores excelentes: cómo mejorar el aprendizaje en América Latina y el Caribe. GRUPO DEL BANCO MUNDIAL: Washington, DC, 2014. 53 p. (Serie del Foro sobre Desarrollo de América Latina)

BRZEZINSKI, Iria (org.). LDB dez anos depois: reinterpretação sob diversos olhares. - 3. ed. São Paulo: Cortez, 2010.

EVANGELISTA, Olinda. Apontamentos para o trabalho com documentos de política educacional. s.d. 16 f. Disponível em http://www.dfe.uem.br/texto.Olinda.PDF Acesso em 20 de fevereiro de 2012.

FAMILIAR, Jorge et al.. Prólogo. In: BRUNS, Barbara; LUQUE, Javier. Profesores excelentes: cómo mejorar el aprendizaje en América Latina y el Caribe. GRUPO DEL BANCO MUNDIAL: Washington, DC, 2014. p. XI-XII. (Serie del Foro sobre Desarrollo de América Latina)

FREITAS, Luiz Carlos de. Os reformadores empresariais da educação: da desmoralização do magistério à destruição do sistema público de educação. Educação \& Sociedade. Campinas, v. 33, n. 119, p. 379-404, abr.-jun. 2012

FRIGOTTO, Gaudêncio. A Produtividade da Escola Improdutiva:um (re)exame das relações entre educação e estrutura econômico-social e capitalista. São Paulo: Cortez, 1984.

Educação e Crise do Capitalismo Real. São Paulo: Cortez, 1995.

HADDAD, Sérgio (org.). Banco Mundial, OMC e FMI: o impacto nas políticas educacionais. São Paulo: Cortez, 2008. 214 p.

LEHER, Roberto. Um novo senhor da educação? A política do Banco Mundial para a periferia do capitalismo. Outubro (São Paulo) São Paulo, v. 1, n. 3, p. 19-30, 1999.

MARX, Karl. Para uma crítica da economia política. Vol. 1. 12. ed. Rio de Janeiro: Bertrand Brasil, 1988.

MAUÉS, Olgaíses Cabral. A política da OCDE para a educação e a formação docente. A nova regulação? Educação, Porto Alegre, v. 34, n. 1, p. 75-85, jan./abr. 2011. Disponível em <http://revistaseletronicas.pucrs.br/ ojs/index.php/faced/article/viewFile/

5033/6130> Acesso em 26 de setembro de 2013.

NEVES, Lúcia Maria Wanderley et al. A formação para o trabalho simples no Brasil contemporâneo: da EDUCAÇÃO PARA TODOS para TODOS PARA A EDUCAÇÃO projeto de pesquisa. Digitado, 2011. 
. O professor como intelectual estratégico na disseminação da nova pedagogia da hegemonia. 2013. 15 p.Disponível em http://36reuniao.anped.org.br/ pdfs_trabalhos_encomendados/gt05_trabencomendado_lucianeves.pdf Acesso em 23 de março de 2014.

PANSARDI, Marcos Vinícius. A formação de professores e o Banco Mundial. EccoS. São Paulo, n. 25, p.127-142, jan./jun 2011. Disponível em <http://www.redalyc. org/pdf/

715/71521708008.pdf>Acesso em 26 de setembro de 2013.

PIRES, Valdemir. Economia da educação: para além do capital humano. Sào Paulo: Cortez, 2005.

SANTOS, Lucíola Licínio de C. P. A implementação de políticas do Banco Mundial para a formação docente. Cadernos de Pesquisa, 111, dezembro 2000, p. 173-182. Disponível em <http://www.scielo.br/scielo.php?script=sci_arttext\&pid=S0100-15742000000300009> Acesso em 16 de fevereiro de 2014.

SAVIANI, Dermeval. História das ideias pedagógicas no Brasil. Campinas: Autores Associados, 2008.

SHIROMA, Eneida Oto; MORAES, Maria C. M de; EVANGELISTA. Política Educacional. Rio de Janeiro: DP\&A, 2000. 140 p. (Coleção o que você precisa saber sobre)

SOARES, Maria Clara Couto. Banco Mundial: políticas e reformas. In:TOMMASI, Livia de; WARDE, Mirian Jorge; HADDAD, Sérgio (org.). O Banco Mundial e as políticas educacionais. São Paulo: Cortez: Ação Educativa, 1996. p. 15-40.

SOUZA, Thaís Rabello de. (Con) formando professores eficazes: a relação política entre o Brasil e a Organização para a Cooperação e Desenvolvimento Econômico (OCDE). Dissertação (Mestrado) - Universidade Federal Fluminense. Faculdade de Educação, 2009. $300 f$.

TOMMASI, Livia de; WARDE, Mirian Jorge; HADDAD, Sérgio (org.). O Banco Mundial e as políticas educacionais. São Paulo: Cortez: Ação Educativa, 1996. 277 p.

WACHOWICZ, Lílian Anna. A dialética na pesquisa em educação. Diálogo Educacional. v. 2 - n.3 - p. 171-181 - jan./jun. 2001.

WERLANG, Adriana da Cunha; VIRIATO, Edaguimar Orquizas. O PROGRAMA PARA REFORMA EDUCACIONAL NA AMÉRICA LATINA E CARIBE (PREAL) E A POLÍTICA DE FORMAÇÃO DOCENTE NO BRASIL NA DÉCADA DE 90. 2012. 17 f. Disponível em <http://www.ucs.br/etc/conferencias/index.php/anpedsul/9an pedsul/paper/viewFile/1468/610> Acesso em 20 de agosto de 2013.

ZEICHNER, Kenneth M. Políticas de formação de professores nos Estados Unidos: com e por que elas afetam vários países no mundo. Belo Horizonte: Autêntica, 2013. 238 p. (Coleção Docência) 
1 Termos aqui utilizados conforme os compreende Marx: o trabalho simples como aquele de natureza indiferenciada, mero dispêndio da força de trabalho que todo homem possui em seu organismo; o trabalho complexo, aquele de natureza especializada, requerendo maior formação do trabalhador (MARX, 1988).

2 Coordenado nacionalmente pelo professor Dr. André Silva Martins (UFJF), o Coletivo de Estudos de Política Educacional conta com quatro Núcleos, distribuídos nos estados do Rio de Janeiro, Minas Gerais, Alagoas e Paraíba, formados por pesquisadores das seguintes instituições, respectivamente: Escola Politécnica de Saúde Joaquim Venâncio - Fundação Oswaldo Cruz; Universidade Federal de Juiz de Fora; Universidade Federal de Alagoas, e Universidade Federal de Campina Grande.

3 O Banco Mundial é composto por um conjunto de organismos: BIRD (Banco Internacional para Reconstrução e Desenvolvimento); IDA (Associação Internacional de Desenvolvimento), IFC (Cooperação Financeira Internacional); ICSID (Centro Internacional para Resolução de Disputas sobre Investimentos); MIGA (Agência de Garantia de Investimentos Multilaterais), e o GEF (Fundo Mundial para o Meio Ambiente).

4 O documento também apresenta propostas para a carreira docente, como sejam: recrutar melhores professores: incrementar a seletividade na docência nos próximos 10 anos, mediante a elevação dos parâmetros para ingresso nos programas de formação docente, a elevação da qualidade dos institutos de formação docente, a elevação dos parâmetros de contratação dos novos professores (p. 23- 34); desenvolver professores de excelência, mediante as tarefas de indução, de avaliação, de desenvolvimento profissional e de gestão (p. 34-40). Tais propostas, no entanto, ultrapassam o âmbito do presente texto.

Recebido: jun/2015 $\quad$ Aprovado: jul/2015 